\title{
A Right to Adaptation: Securing the Participation of Marginalised Groups
}

\author{
Emily Polack
}

\begin{abstract}
1 Introduction
While climate change does not discriminate among lines of class, caste, age, sex, physical abilities or financial insecurity, it is exacerbating existing inequalities and driving those with poor adaptive capacity into deeper conditions of vulnerability to shocks and stresses. Understanding how climate change impacts intersect with people's marginalisation remains limited, as vulnerability assessments have been largely concerned with fragile ecosystems and considered along sectoral lines. Whilst common but differentiated responsibilities between nations is a founding principle of the UN Climate Change Convention, differentiated human dimensions of climate change are only now starting to assume centre stage, buoyed by the launch of the Global Alliance for Climate Justice of the Global Humanitarian Forum (2008), through which Kofi Annan and several hundred participants 'agreed to support efforts to establish climate justice as the guiding principle for a post-Kyoto global climate agreement'.
\end{abstract}

This late recognition of climate change as a set of social justice issues indicates a failure of the international climate regime to adequately realise these perspectives, and deliver adequate adaptation assistance to those who are being affected the most and have least responsibility for global climate change. These failures are being reflected in the increasing application of international human rights frameworks to politicise the poverty and inequality dimensions of tackling climate change and provide channels for challenging the power relations that have created conditions of severe inequality. Human rights and development professionals are developing minimum standards and thresholds for determining rights and responsibilities. These are taking debates beyond the international (developed vs. developing) to the national and sub-national level and therefore potentially to the level of groups and individuals (ICHRP 2008; Baer et al. 2007).

Women, children, pastoralists, disabled people or indigenous peoples are often said to be the poorest of the poor and therefore the most vulnerable (IPCC 2007; ADB et al. 2003), but strategies for addressing climate risks and vulnerabilities of certain poor and marginalised groups are under-researched. If policy responses are to be sensitive to the experiences of the groups and not exacerbate conditions of inequality this gap must be addressed. This article looks at this process of differentiation, and the use of a human rights lens by organisations supporting, promoting or advocating the rights of certain groups identified as the 'most vulnerable to climate change'.

This article takes the first step towards seeing how principles of procedural justice, recognition and inclusion and individual and group rights frameworks might lead to policymaking, policy outcomes and programming that offer pathways out of poverty, and seize another policy-space that is in theory dedicated to overcoming unequal power relations.

\section{Labelling - a disempowering discourse?}

This article does not intend to aggregate literature from different interest groups to compare their experiences (clearly impossible due to multiple identities and heterogeneity of all 'groups'). Instead, it aims to highlight participatory and rights-based approaches, which special interest groups have applied. Most of the literature disclaims homogenisation of groups and calls for local and contextualised research and interventions. 
'Labelling' is a highly contested area. In development discourses, its use has been justified as a means to assess (Eyben and Moncrieffe 2008). Here, it is used for obtaining an insight into the differentiation of citizen actors in terms of their specific basket of climate change - related vulnerabilities and their capacities to influence policy. In turn this may also inform effectiveness of adaptation funding delivery. By integrating this with an examination of rights and participation strategies a degree of 'labelling' is justified based on seeking opportunities within adaptation debates for challenging power relations. However, it is also important to highlight the potential damage caused by continually labelling a certain group as 'the most vulnerable', or related calls for adaptation policy to target 'the most vulnerable'. While the reports of special interest groups emphasise the impacts of climate change and the potential for climate change to exacerbate existing inequalities, this runs counter to language of capabilities, recognition, empowerment and equity that seek to overcome structural inequalities. This form of labelling may instead justify 'top-down needs based interventions' (Eyben and Moncrieffe 2008). Can instead, identity politics and recognition in this case contribute to redistribution of both power and access to greater adaptive capacity?

\section{Justice and equity in international climate policy}

Increasing theorisation of climate justice is drawing on broad theories of justice (e.g. Rawls' Theory of

Justice as Fairness), development theories (e.g. Sen's Capability Approach) and other principles central to international environmental law (e.g. polluter pays principle). A core principle running through the International Climate Change regime is one of 'common but differentiated responsibility'. Because of global inequalities between states, there has been a considerable focus on 'procedural justice', i.e. the need to 'construct mechanisms that will ensure that a just solution can be reached' (ICHRP 2008). While distributional justice is theoretically being addressed through the responsibility of wealthy countries to provide adaptation assistance to developing countries, further advancements in procedural justice are essential to realising distributional justice fully.

These theories and principles have been predominantly applied at a level of nation-states in the international arena and based on inequalities in North-South experiences of climate change impacts, responsibility for pollution, access to carbon-intensive and renewable energy technologies, and negotiating power. Differentiating populations at a national, subnational or transnational level along vulnerability, identity or capability lines and applying principles of justice and equity have been limited. This becomes more relevant once adaptation finance flows become more established. Research on how such a 'common but differentiated responsibility' approach at different scales could inform the rights of different groups to adaptation finance is needed.

\section{Differentiating vulnerability}

'The most vulnerable' groups, by lacking a voice and influence in climate change policymaking, are unlikely to receive the support they need as policies are less likely to account for their particular experiences. This is likely to exacerbate their position of marginalisation or vulnerability further. Furthermore, the same groups have done least to cause climate change, providing a moral grounding for attention to their needs. While the likelihood of experiencing poverty and exclusion from decision-making characterises vulnerability of most disadvantaged identities, naturally each has its own set of conditions which limit the resilience and adaptive capacity of many people holding that identity. Multiple layers of identity prevent any one group of people as being labelled 'the most vulnerable'.

However, there is an important issue of recognition at play. International policy debates have made sparse reference to these different groups and commonly they are referred to as passive or helpless victims. Disaggregating impacts of climate change by gender, ethnicity, age and disability has been a first step in tackling this, and empirical research is still in its early stages. ${ }^{1}$ Minority Rights Group International found no English language research on how global warming is affecting minority groups (MRG 2008). To challenge this further, most of the emerging literature relevant to these groupings includes a discussion of their unique experiences, knowledge and capacities (Mitchell et al. 2007; CCC 2008; MRG 2008; Salick and Byg 2007).

While empirical research is limited, special interest groups have drawn on existing literature on approaches to understanding certain groups' experiences of poverty, marginalisation and discrimination, and applied experience of how development theory and practice has tried to overcome these conditions. Gender and 
development theory is highly advanced and can easily be drawn upon in new emerging contexts; women's vulnerability to climate change is expected to stem from their limited access to 'financial resources, land, education, health and other basic rights ... and are seldom involved in decision-making processes' (Demetriades and Esplen, this IDS Bulletin).

Demetriades and Esplen suggest less is known about the distinct vulnerabilities of men and boys to climate change.

Children's vulnerabilities as dependants and nonvoters have also been theorised (Ansell 2005), and in relation to climate change, knowledge of children's vulnerability in disasters has been extensively drawn upon (CCC 2008; Save the Children 2008; Bartlett 2008). UNICEF (2008) summarises the challenges posed by climate change to achieving the MDGs, several of which relate directly to children's wellbeing, including reducing child and maternal mortality rates. Children's vulnerability relates to intergenerational transfer of poverty and the potential impact on children's future employment, and chances of migration, being involved in conflict and experiencing extreme climatic events.

Given the limited research on how climate change impacts disabled people, Leonard Cheshire International is also drawing on the experiences of disabled people in disasters and the vulnerabilities associated with unequal access to basic services, and financial constraints faced by families of disabled people. 'Due to a combination of discrimination and invisibility, disabled people have not had equal access to many mainstream preparedness, mitigation and emergency interventions' (Kett et al. 2005).

The literature on indigenous people and minorities and climate change draws upon their welldocumented close relationship to nature and dependence on natural resources. Indigenous people are bearing the brunt of climate change and are particularly vulnerable due to their location in sensitive zones including 'polar and arid zones, forest, wetland, river and coastal areas' (Indigenous Peoples' Statement, cited in Tauli-Corpuz and Lynge 2008). Indigenous people are also more vulnerable to mitigation responses to climate change (e.g. expansion of biofuel production, seeking of carbon sinks, large-scale renewable energy projects and mechanisms associated with reducing emissions through deforestation and degradation (REDD).
From a procedural justice perspective, these vulnerabilities are reflected in different groups' invisibility in climate change policy-processes. For example, only 12 per cent of heads of delegation were women (Brody et al. 2008) and no disability organisations are registered as observers to the UN Framework Convention on Climate Change (UNFCCC) (Kett, personal communication 2008).

\section{Mitigation and adaptation through a human rights lens}

Climate change is causing human rights violations. The international community, particularly those responsible for high levels of carbon emissions, have a responsibility to halt the violation at source, and are therefore clearly the duty-bearers of rights to both mitigation and adaptation. Rights to mitigation may manifest in expressions of a right to life-supporting commons (Baer 2006), and rights to decide how one's carbon credits are spent. ${ }^{2}$ This article however, investigates approaches to differentiated rights to adaptation. This means applying a human rights lens to minimising climate risks and enhancing adaptive capacity, whether delivered through adaptation projects or programmes or climate change-resilient development.

Climate-resilient development necessitates the protection of basic human rights, namely those set out in the International Bill of Rights. These deal with rights to water, health, shelter and food amongst others. Disaster risk reduction literature shows how a 'right to safety' or 'absence from danger' are also adequately established by international human rights frameworks (Adger et al. 2006; Twigg 2003). New articulations of rights in a climate change context, besides mitigation, include a right to adaptation, to compensation, to pollute/to a portion of the atmosphere and to 'reach a dignified level of sustainable human development' (Baer et al. 2007).

The limitation is in realising these rights and this extent of protection. Particularly in developing countries as governments, though primary dutybearers, are only required to protect, promote and fulfil the rights of citizens within the limits of available resources. However, rights-based analysis is powerful in politicising apparent injustices and draws attention to duty-bearers and the causes of vulnerability (Blackburn et al. 2005). The ICHRP (2008) similarly states that a human rights lens on climate justice debates and the lack of progress in minimising risks to 
the most vulnerable provides 'a shared and legally codified moral language' among states.

A human rights approach also assists in shifting the lens to the individual and therefore assists differentiation. This supports the case made by Baer et al. (2007), who suggest the 'right to development in a climate-constrained world' should be considered at the level of the individual. In this context, human rights provide clearer minimum thresholds for rights and responsibilities, where the most vulnerable have a greater right to development (including development that is climate resilient) than they have responsibility for reducing greenhouse gas emissions. Applying group rights regimes - for example the UN Conventions on the Rights of the Child (UNCRC), on the Elimination of all forms of Discrimination Against Women (CEDAW), on the Rights of Persons with Disabilities or the Declaration on the Rights of Indigenous Peoples - facilitates citizen engagement and provides frameworks for calling the state and the international community to account.

Not surprisingly then, most reports and communications about vulnerable groups and climate change draw on the respective treaties to call on states to facilitate their participation and recognise, protect and promote their unique set of rights. For children, for example, having their right to education is all the more urgent given that their future employment options are more uncertain than ever, and specific technical skills will be required to prepare them for a low carbon future and adaptation to climate change. Children in a Changing Climate (CCC 2008) talks of investing in 'education as insurance' as a policy prescription. Furthermore, according to UNICEF (2008) 'children have the absolute right to live in a decent environment with all that implies: attending school, enjoying good health and living and growing in safety. This is not simply a moral assertion. It is codified in the UN Convention on the Rights of the Child (CRC) - the world's most widely ratified human rights treaty'.

\section{Realising rights to participate in adaptation} Whilst the literature reports broad rights-based analysis, emphasising rights to participate in adaptation policy processes generally dominates. The literature also reflects instrumentalist approaches to participation. Identifying pathways for realising participatory rights for different groups aims to highlight opportunities and expose barriers to participation at multiple scales. Here, we focus on the international and national level, but recognise that considerable efforts are being made to enable marginalised groups to lead adaptation projects at a local level (e.g. see CCC 2008; Mitchell et al. 2008; Save the Children 2008).

\subsection{International level}

Stronger participation and negotiating capacity of developing country states is critical but the extent to which this can facilitate the participation and representation of disadvantaged groups is unclear.

Opportunities for participation at the level of 'observer' at the UNFCCC is reasonably extensive, with Article 7 providing for attendance of 'any body or agency, whether national or international, governmental or non-governmental, which is qualified in matters covered by the Convention'. Observer status allows attendees to observe formal negotiations and participate in the Side Event series organised parallel to the negotiations. Organisations - predominantly international non-governmental organisations (NGOs) - have seized this opportunity for representatives of marginalised groups to present their experiences of climate change, become familiar with the international policy processes and voice their policy demands.

For example, ActionAid, the Women's Environment \& Development Organization (WEDO) and other organisations working on gender justice have supported the attendance of women 'living on the frontline' of climate change. Children in a Changing Climate supported the attendance of children as 'observers' at both COP-13 (2007) and the UNFCCC meetings in Bonn in 2008. No disabled people's organisations attended COP-13, but this has now been identified as a gap to be filled at future meetings. Other initiatives to develop policy messages include summits or conferences prior to or parallel to the UN negotiations, and delivering declarations and policy messages to conference delegates (often via the media, e.g. UNICEF children's summit). These processes raise the profile of group agendas and may be picked up by delegates, but there is little research on how events during the negotiations influence outcomes.

Salick and Byg call for 'self-representation of Indigenous People in Climate Change Forum' (2007). Participation may come in the form of contributing 
to global knowledge banks on Traditional Ecological Knowledge (TEK). This is advanced further by the special rapporteurs' recommendation that 'full and effective participation of indigenous people in the forthcoming negotiations for the next Kyoto Protocol commitment period should be ensured' (Tauli-Corpuz and Lynge 2008: recommendation 83). Perhaps, with more relevance to adaptation 'a Working Group on Indigenous Peoples and Climate Change' should be established within the UNFCCC'. Minorities and indigenous people are likely to be more successful in realising their rights to participation based on their role as stewards of precious natural environments (MRG 2008), but risk being used as instruments of mitigation by more powerful political actors, rather than gaining adaptation assistance themselves.

The ActionAid International/IDS report on women's role in adaptation (Mitchell et al. 2007) focuses its recommendations on women's influence in adaptation financing. It recognises that for adaptation funds to assist the most vulnerable people, the interests of different groups must be represented in the governance of different adaptation funding mechanisms.

Children in a Changing Climate is proposing that children are enabled to sit on delegations to 'remind delegates on whose behalf they are negotiating' (Hall, cited in Polack 2008). Initial communications imply the UNFCCC Secretariat is responsive to these kinds of initiatives, recognising that an effective global climate change deal in the tight policy timeframe might require new and innovative processes. However, the systemic inequalities in representation of developing countries in the negotiations (some countries are unable to send more than one negotiator) means that justifying financial resources for non-professional negotiators to be on the delegation, such as children, is harder for parties to justify.

\subsection{National level}

The National Adaptation Programmes of Action (NAPAs) being developed by the least developed countries (LDCs) have been designed to build ownership and maximise participation in in-country adaptation. The process gives prominence to 'community-level input as an important source of information, recognising that grassroots communities are the main stakeholders' (UNFCCC). The guidelines for preparing NAPAs emphasise the participation of men and women at the grassroots, again both for effective policymaking and because the adaptation process is theoretically designed to improve their situation. Still in the early stages, with some LDCs still without NAPAs, there has been little systematic analysis of the consultation processes that have taken place. Participants in one review in Eastern and Southern Africa acknowledged the contribution made by participatory, bottom-up approaches to ownership.

The teams agreed that the steps leading to the formulation of the NAPA have worked well, particularly stakeholder identification, focusing on the most vulnerable groups in different sectors/regions, involvement of planners and policy makers and the provision of platforms for discussion and consultation between them.

(Osman-Elasha and Downing 2007)

However the broader notions of equity and justice related here to the experiences of politically or socioeconomically marginalised groups, and the opportunities for challenging persistent unequal power relations have not materialised.

Adaptation as a right based on equitable sharing of the global climate change burden, or the notion of a deficit in adaptation are not prominent in the NAPA proposals. The broader framing of sustainable development is implicit in some respects (e.g., focus on poverty reduction and stakeholder engagement). Actions for reducing conflict, institutional and structural reforms, and empowerment of disadvantaged communities are not widely reflected in the NAPAs. (Osman-Elasha and Downing 2007)

Minority Rights Group International (MRG 2008) made preliminary enquiries into representation of minority groups in the NAPA consultation process and found little evidence. However, NAPAs and National Communications are still identified as an important opportunity for participation of different groups in national level plans. NAPAs comprise a selection of priority adaptation projects, therefore influencing this process could be vital in any one community or group receiving adaptation assistance. The review cited above noted that none of the NAPAs prioritised 'including climate change in curriculum at different education levels or promoting indigenous knowledge as a basis for adaptation 
projects'. This likely reflects a lack of meaningful participation of those engaged with children's rights to adaptation (Osman-Elasha and Downing 2007).

This brief review highlights major gaps in evidence of opportunities for or barriers to participatory rights in national level adaptation policy processes and calls for monitoring impacts of diverse strategies for overcoming barriers to participation in international policy arenas.

\section{$7 \mathrm{~A}$ rights and participation agenda}

This article has reviewed the emerging literature on groups identified as 'the most vulnerable' to climate change, learning that being 'the most vulnerable' is a function of poverty, dependence, discrimination and political marginalisation. It does not present strategies for advancing the position of such groups at this stage, except by highlighting opportunities. The next step is to integrate some of these issues into the other approaches written about in this IDS Bulletin. For example, we can ask how adaptive social protection or climate change-sensitive microfinance applies to children, or how the vulnerability of certain groups can be reduced through making a pro-poor economic case for adaptation programming. Furthermore, understanding the livelihood contexts of different groups and their poverty categories and then tailoring support to particular climate change adaptation strategies is an important step in addressing the experiences of marginalised groups. If adaptation to climate change is about increasing 'options' and 'facilitating better livelihoods contexts' (Sabates-Wheeler et al., this IDS Bulletin) as opposed to preparing for a set of possible climate change scenarios, individuals assessing 'opportunities' based on their multiple identities and multiple pathways for claiming rights should contribute to climate-resilient development for all.
The following list represents an agenda for progressing participation and rights to ensure adaptation policymaking and policy outcomes at every scale are seized as opportunities for shifting power relations, reducing vulnerabilities, and preventing mal-adaptation.

- Conduct further analysis into opportunities for, barriers to, and the potential of greater participation and inclusion of marginalised groups in NAPAs and other adaptation policy processes, including adaptation finance delivery.

- Consider how strategic programmes organised around 'vulnerable groups' (e.g. Children in a Changing Climate, Women for Climate Justice) are strengthening their participation in national and international climate change policy processes, and how other groups could learn from these.

- Better analyse and employ the role of multiple legal regimes (e.g. international environmental law or forms of 'people's law'), in strengthening the position of marginalised groups within climate change negotiations and achieving climateresilient development for all. For example the ICHRP (2008) applies the Aarhus Convention to realising a right to information and public participation in climate change which could be made relevant to particular groups and policy processes at different scales.

- Draw further from social exclusion and inclusion in development literature and integrate this with adaptation policy contexts.

- Support communications tools that effectively convey the impacts of climate change on particular vulnerable groups, but also facilitate groups to demonstrate their sophisticated understanding of adaptation options to articulate their needs in policy spaces. 


\section{Notes}

1 Gender and climate change perhaps hosts the most advanced body of literature, but is still limited, see Demetriades and Esplen (this IDS Bulletin) and www.gendercc.net for climate change and gender literature.

2 'Even if we accept that carbon offsetting is worth doing, when it comes to small-scale development

\section{References}

ADB (African Development Bank); Asian Development Bank; Department for International Development: United Kingdom; Directorate-General for International Cooperation: the Netherlands; Directorate General for Development: European Commission; Federal Ministry for Economic Cooperation and Development: Germany; Organisation for Economic Co-operation and Development; United Nations Development Programme; United Nations Environment Programme; World Bank (2003) Poverty and Climate Change: Reducing the Vulnerability of the Poor Through Adaptation, www.undp.org/energy/ povcc.htm (accessed 8 July 2008)

Adger, N.; Paavola, J.; Huq, S. and Mace, M.J. (eds) (2006) Fairness in Adaptation to Climate Change, Massachusetts: MIT Press

Ansell, N. (2005) Children, Youth and Development, Oxford: Routledge

Baer, P. (2006) 'Adaptation: Who Pays Whom?', in N. Adger, J. Paavola, S. Huq and M.J. Mace (eds) (2006) Fairness in Adaptation to Climate Change, Massachusetts: MIT Press

Baer, P.; Athanasiou, T. and Kartha, S. (2007) The Right to Development in a Climate Constrained World, The Greenhouse Development Rights Framework, with the support of Christian Aid and the Heinrich-Böll-Foundation, www.ecoequity.org/ docs/TheGDRsFramework.pdf (accessed 9 July 2008)

Bartlett, S. (2008) Climate Change and Urban Children: Impacts and Implications for Adaptation in Low and Middle Income Countries, International Institute for Environment and Development (IIED) Human Settlements Discussion Paper - Climate Change 2, IIED, www.iied.org/pubs/display.php?o= 10556IIED (accessed 8 July 2008)

Blackburn, J.; Brocklesby, M.J.; Crawford, S. and Holland, J. (2005) 'Operationalising the Rights Agenda: Participatory Rights Assessment in Peru and Malawi', IDS Bulletin 36.1: 91-9, January projects, whose carbon is it? Who has the right to decide whether emission reductions should be sold to company $\mathrm{A}$ or $\mathrm{B}$, and who has the right to decide how the revenue is deployed?' (Scott 2007).

Brody, A.; Demetriades, J. and Esplen, E. (2008) Gender and Climate Change: Mapping the Linkages, Scoping Study on Knowledge and Gaps, Brighton: BRIDGE

CCC (2008) A Right to Participate: Securing Children's Role in Climate Change Adaptation, London: Children in a Changing Climate

Eyben, R. and Moncrieffe, J. (2008) The Power of Labelling in Development Practice, IDS Policy Briefing, 28 April

Global Humanitarian Forum (2008) Kofi Annan Launches Alliance for Climate Justice, 25 June, www2.ghf-ge.org/news/index.cfm (accessed 3 July 2008)

ICHRP (2008) Climate Change and Human Rights: A Rough Guide, Versoix: International Council on Human Rights Policy

IPCC (2007) Climate Change 2007: Synthesis Report, R.K. Pachauri and A. Reisinger (eds), Geneva: Intergovernmental Panel on Climate Change Kett, M.; Stubbs, S. and Yeo, R. (2005) Disability in Conflict and Emergency Situations: Focus on Tsunami-affected Areas, International Disability and Development Consortium Research Report, submitted to KaR Disability Programme, Overseas Development Group, University of East Anglia, www. disabilitykar.net/research/thematic_conflict. html (accessed 8 July 2008)

Mitchell, T.; Haynes, K.; Hall, N.; Choong, W. and Oven, K. (2008) 'The Role of Children and Youth in Communicating Disaster Risk', Children, Youth and Environment 18.1: 254-79

Mitchell, T.; Tanner, T. and Lussier, K. (2007) 'We Know What We Need!' South Asian Women Speak Out on Climate Change Adaptation, Action Aid International and IDS, www.ids.ac.uk/UserFiles/ File/poverty_team/ActionAid_IDS_Report_We_ know_what_we_need_South_Asian_women_ speak_out_on_climate_change_adaptation.pdf (accessed 8 July 2008)

MRG (Minority Rights Group International) (2008) State of the World's Minorities 2008: Climate 
Change Special, www.minorityrights.org/?lid=6138 (accessed 9 July 2008)

Osman-Elasha, B. and Downing, T.E. (2007) Lessons Learned in Preparing National Adaptation Programmes of Action in Eastern and Southern Africa, European Capacity Building Initiative, Policy Analysis Report, Oxford: European Capacity Building Initiative

Polack, E. (2008) Empowering Children to Tackle Climate Change, IDS and Partners Launch New Programme at UN Climate Negotiations, News at IDS, 13 June 2008, www.ids.ac.uk/index.cfm? objectid=82821BA9-086F-BFE5-B9774B839FD2 A75D (accessed 9 July 2008)

Salick, J. and Byg, A. (eds) (2007) Indigenous Peoples and Climate Change, report of a symposium, 12-13 April, Oxford: Tyndall Centre, www.tyndall.ac.uk/ publications/Indigenouspeoples.pdf (accessed 9 July 2008)

Save the Children (2008) In the Face of Disaster: Children and Climate Change, London: International Save the Children Alliance
Scott, A. (2007) 'Is Offsetting Bona Fide Development?', talk given to Tyndall Centre, 5 September

Tauli-Corpuz, V. and Lynge, A. (2008) 'Impact of Climate Change Mitigation Measures on Indigenous Peoples and on their Territories and Lands', submission to ECOSOC Permanent Forum on Indigenous Issues, seventh session, New York, 21 April-2 May

Twigg, J. (2003) The Right to Safety: Some Conceptual and Practical Issues, Benfield Hazard Research Centre, Disaster Studies Working Paper 9, London BUHRC, www. benfieldhrc.org/disaster_ studies/working_papers/pdfs/workingpaper9.pdf (accessed 8 July 2008)

UNICEF (2008) Our Climate, Our Children, Our Responsibility: The Implications of Climate Change for the World's Children, UNICEF Climate Change Report 2008

UNFCCC http://unfccc.int/national-reports/napa/ items/2719.php (accessed 5 July 2008) 